\title{
Contribution of ethanol and cigarette smoking to pulmonary dysfunction in chronic alcoholics
}

\author{
DJ LYONS, SUSANNAH V HOWARD, JS MILLEDGE, TJ PETERS
} From the Divisions of Anaesthetics and Clinical Cell Biology, Medical Research Council Clinical Research
Centre, Harrow

ABSTRACT Ethanol is claimed to have a specific damaging effect on the lung and to be at least partially responsible for pulmonary dysfunction in alcoholics. Adequate allowance for the damaging effects of cigarette smoking has not, however, been made hitherto. Pulmonary function studies were undertaken in 27 alcoholic subjects. Although there was a high prevalence of symptoms and abnormalities of pulmonary function, these were largely confined to current smokers: most of those who had never smoked and the ex-smokers who were symptom free and had normal pulmonary function. A case controlled study of alcoholics and matched controls showed no significant difference in pulmonary function between the two groups. It is concluded that the high prevalence of respiratory disease in alcoholics is largely attributable to their smoking habits: no evidence of a specific pulmonary toxic effect of ethanol was identified in the study.

"Whisky bronchitis" is a colloquial expression used to describe the high prevalence of respiratory disease in alcoholics. Chronic bronchitis, emphysema, aspiration pneumonia, and pulmonary tuberculosis are all more common in alcoholics than in nonalcoholics. ${ }^{1}$ Several explanations for these observations have been offered, including the smoking habits of alcoholics, ${ }^{2}$ ventilation-perfusion mismatch, ${ }^{3}$ poor nutritional state, and multiple thoracic cage injuries. Recently it has been postulated that ethanol has a specific toxic effect on the lung, ${ }^{4}$ and this hypothesis has generated a search for alterations in the pulmonary function of alcoholics ${ }^{5-7}$ that are independent of the above effects.

A major difficulty has been the separation of the effects of tobacco from those of pulmonary damage caused by alcohol. At least $80 \%$ of alcoholics are current smokers, ${ }^{5-7}$ and many smoke very heavily. We have therefore studied the pulmonary function of a series of alcoholics grouped according to their smoking habit. In addition, a case-control study of alcoholics, individually matched for age, height, race, sex, and smoking habit, was performed in an attempt to identify any possible direct pulmonary toxic effect of ethanol.

Address for reprint requests: Dr TJ Peters, Division of Clinical Cell Biology, MRC Clinical Research Centre, Watford Road, Harrow, Middlesex HAl 3UJ, UK.

Accepted 25 November 1985

\section{Methods}

We studied 27 patients who were referred for assessment and treatment of various alcohol related problems. No criteria of maximum or minimum alcohol intake were set, the diagnosis of alcoholism being based on physical, social, and psychological deterioration caused by prolonged heavy drinking. Most patients, however, had consumed more than $100 \mathrm{~g}$ ethanol a day for at least three years. Thirteen of the 27 alcoholic patients were smokers. The first 17 patients studied were a consecutive series of referrals (they included four current non-smokers). Subsequently only current non-smokers were studied. Three patients were excluded, two because their vital capacity was too low to permit an accurate determination of transfer factor ( $\mathrm{TLCO}^{8}$ and one because allergic asthma made sequential studies during abstinence unreliable. For each alcoholic patient entered in the study a control patient was recruited, matched for age, sex, height, race, and smoking habit (that is, whether currently, previously, or never a smoker). Exclusion criteria for controls were the same as those for alcoholics and one control subject was excluded from the study because of a low vital capacity. In addition, patients giving a history of consuming more than $30 \mathrm{~g}$ of ethanol a day were excluded from the control group. Most of the control subjects were patients who were making a routine outpatient visit to the hospital and were seen several weeks after 
admission to an infectious disease unit because of non-respiratory problems. The remaining control patients were attending the outpatient department after an admission to hospital for diabetes or orthopaedic disorders.

All of the study and control patients were questioned about their drinking and smoking habits. The British Medical Research Council respiratory questionnaire $^{9}$ was used to assess respiratory symptoms in the alcoholics. Alcohol consumption was expressed in terms of grams per day; beer was considered to be $5 \%$ ethanol, wine $11 \%$, and spirits $40 \%$. Cigarette smoking was recorded as pack years. The patients who had stopped smoking for at least one year are referred to as current non-smokers.

A chest radiograph was obtained in all cases. Spirometric measurements were made with a dry bellows spirometer. The forced expiratory spirograms were inspected and the best of three determinations of FEV $_{1}$ and forced vital capacity (FVC) was used for analysis. Lung volumes were measured by helium dilution, and TLCO was measured in the sitting position by the single breath method described by Ogilvie. ${ }^{10}$ In smokers venous carboxyhaemoglobin was measured (Instrumentation Laboratories Co Oximeter). TLCo was not corrected for "back pressure" of venous carboxyhaemoglobin since, even at the highest levels encountered, the correction would be less than the coefficient of variability of the test (about 5\%). Arterial blood was taken in the supine position from the smokers with the patient breathing $\stackrel{\otimes}{\times}$ room air, and gas tensions were measured on an automatic analyser (Instrumentation Laboratories 613). S

Observed values that differed from the predictedo normal by more than $20 \%$ were considered abnor- $\underline{\bar{T}}$ mal. For men and women originating from India nor- $-\frac{\bar{s}}{2}$ mal values were taken from Miller ${ }^{11}$ and for those of ${ }^{\Phi}$ European origin from Cotes. ${ }^{8}$ A low (less than $80 \%$ ळ predicted normal for age) ratio of $\mathrm{FEV}_{1}$ to $\mathrm{FVC}$ was taken to indicate an obstructive defect. A low (less. than $80 \%$ predicted normal) TLCo together with a $\overrightarrow{\vec{\omega}}$ low (less than $80 \%$ predicted normal) residual volume (RV) and a high $\mathrm{FEV}_{1} / \mathrm{FVC}$ ratio indicated $\mathrm{a} \underset{\times}{\vec{x}}$ restrictive defect. Where a low transfer factor $A$ occurred in the presence of otherwise normal pul- $\vec{\omega}$ monary function this is classified as an isolated diffusion defect.

A liver biopsy was performed, where indicated, as응 part of the clinical assessment of the patient's liver disease. All patients were asked to abstain from alco- $?$ hol and to attend for repeat studies at intervals of $\frac{\hat{a}}{\frac{0}{3}}$ four and 12 weeks. Statistical analyses were per- $\supset$ formed by methods derived from the normal distribu- $\overrightarrow{0}$ tion (Student's paired $t$ test). These studies were approved by the Harrow Health Authority ethical committee.

\section{Results}

The toxic effect of ethanol in the 27 alcoholic patients

Table 1 Smoking habit, alcohol consumption and results of laboratory investigations in alcoholic patients

\begin{tabular}{|c|c|c|c|c|c|c|c|c|}
\hline $\begin{array}{l}\text { Patient } \\
\text { No }\end{array}$ & Age & Sex & Smoking & $\begin{array}{l}\text { Alcohol consumed } \\
\text { (g/day) }\end{array}$ & $\begin{array}{l}M C V \\
(f l)\end{array}$ & $\begin{array}{l}G G T \\
(I U / l)\end{array}$ & $\begin{array}{l}A S T \\
(I U / l)\end{array}$ & Liver histology \\
\hline $\begin{array}{r}1 \\
2 \\
3 \\
4 \\
5 \\
6 \\
7 \\
8 \\
9 \\
10 \\
11 \\
12 \\
13 \\
14 \\
15 \\
16 \\
17 \\
18 \\
19 \\
20 \\
21 \\
22 \\
23 \\
24 \\
25 \\
26 \\
27\end{array}$ & $\begin{array}{l}33 \\
34 \\
37 \\
39 \\
39 \\
44 \\
51 \\
51 \\
53 \\
55 \\
57 \\
58 \\
62 \\
38 \\
39 \\
40 \\
44 \\
45 \\
46 \\
48 \\
49 \\
54 \\
59 \\
38 \\
38 \\
47 \\
48\end{array}$ & $\begin{array}{l}\text { M } \\
\text { M } \\
\mathbf{F} \\
\mathbf{M} \\
\mathbf{M} \\
\mathbf{F} \\
\mathbf{F} \\
\mathbf{M} \\
\mathbf{M} \\
\mathbf{M} \\
\mathbf{M} \\
\mathbf{M} \\
\mathbf{M} \\
\mathbf{M} \\
\mathbf{M} \\
\mathbf{M} \\
\mathbf{M} \\
\mathbf{M} \\
\mathbf{M} \\
\mathbf{M} \\
\mathbf{M} \\
\mathbf{M} \\
\mathbf{F} \\
\mathbf{F} \\
\mathbf{F} \\
\mathbf{M}\end{array}$ & $\begin{array}{c}\text { Current } \\
, " \\
, " \\
, " \\
, \\
\text { Ex-smoker } \\
, " \\
, " \\
, \\
, \\
, \\
, \\
\text { Never } \\
\text { ", }\end{array}$ & $\begin{array}{r}120 \\
300 \\
80 \\
300 \\
200 \\
280 \\
200 \\
150 \\
280 \\
160 \\
120 \\
300 \\
320 \\
250 \\
100 \\
300 \\
100 \\
160 \\
300 \\
160 \\
130 \\
160 \\
200 \\
160 \\
150 \\
100 \\
210\end{array}$ & $\begin{array}{r}94 \\
95 \\
101 \\
93 \\
98 \\
93 \\
90 \\
102 \\
95 \\
102 \\
91 \\
102 \\
94 \\
89 \\
93 \\
90 \\
97 \\
95 \\
99 \\
91 \\
91 \\
98 \\
84 \\
102 \\
94 \\
98 \\
78\end{array}$ & $\begin{array}{r}226 \\
39 \\
61 \\
60 \\
56 \\
30 \\
263 \\
151 \\
123 \\
88 \\
110 \\
39 \\
149 \\
71 \\
292 \\
78 \\
68 \\
87 \\
1353 \\
60 \\
22 \\
66 \\
108 \\
953 \\
36 \\
585 \\
205\end{array}$ & $\begin{array}{r}198 \\
24 \\
24 \\
103 \\
26 \\
37 \\
66 \\
109 \\
37 \\
40 \\
42 \\
19 \\
93 \\
24 \\
42 \\
26 \\
34 \\
60 \\
85 \\
40 \\
22 \\
48 \\
32 \\
136 \\
43 \\
131 \\
44\end{array}$ & $\begin{array}{l}\text { Fatty } \\
\text { NP } \\
\text { Fibrosis } \\
\text { NP } \\
\text { Fatty } \\
\text { Fatty } \\
\text { NP } \\
\text { Fibrosis } \\
\text { Fatty } \\
\text { Fatty } \\
\text { Hepatitis } \\
\text { Iron excess } \\
\text { Fatty } \\
\text { NP } \\
\text { Fatty } \\
\text { Fatty } \\
\text { NP } \\
\text { Fatty } \\
\text { NP } \\
\text { Fibrosis } \\
\text { NP } \\
\text { Fatty } \\
\text { Cirrhosis } \\
\text { Cirrhosis } \\
\text { Fatty } \\
\text { Cirrhosis } \\
\text { Fatty }\end{array}$ \\
\hline
\end{tabular}

MCV-mean corpuscular volume (normal range 80-92 fl); GGT-serum gamma glutamyltransferase activity (normal range 0-50 IU/l); AST - serum aspartate aminotransferase activity (normal range 10-35 IU/1); NP-histological examination not performed. 
Table 2 Clinical details and results of lung function testing of matched alcoholic and control groups (means with one standard deviation in parentheses, corrected to BTPS)

\begin{tabular}{|c|c|c|c|c|}
\hline & $\begin{array}{l}\text { Alcoholics } \\
(n=27)\end{array}$ & $\begin{array}{l}\text { Controls } \\
(n=27)\end{array}$ & $p$ & $\begin{array}{l}95 \% \text { confidence interval } \\
\text { for differences between } \\
\text { means }\end{array}$ \\
\hline 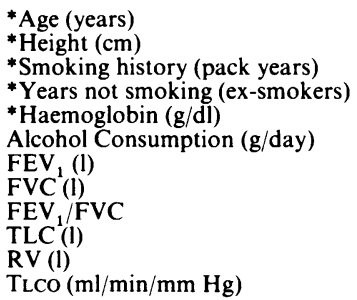 & $\begin{array}{l}46.2(8.2) \\
173(8.6) \\
29.8(14.0) \\
10.0(6.9) \\
14.9(2.1) \\
196(77) \\
2.9(0.9) \\
3.7(1.1) \\
79(7.5) \\
5.8(1.8) \\
2.3(0.7) \\
24.0(6.5)\end{array}$ & $\begin{array}{l}44.0(12.7) \\
175(8.1) \\
31.3(14.0) \\
7.8(4.3) \\
13.8(1.6) \\
24(19) \\
3.0(0.9) \\
4.0(1.0) \\
77(11.3) \\
5.7(1.7) \\
2.1(0.8) \\
25.1(6.5)\end{array}$ & $\begin{array}{l}0.22 \\
0.17 \\
0.92 \\
0.64 \\
0.08 \\
6 \times 10^{-12} \\
0.76 \\
0.94 \\
0.32 \\
0.48 \\
0.54 \\
0.32\end{array}$ & $\begin{array}{l}0.7 \text { to } 2.1 \\
0.7 \text { to } 4.6 \\
-7.8 \text { to } 3.4 \\
-3.3 \text { to } 7.6 \\
-0.1 \text { to } 1.7 \\
102 \text { to } 236 \\
-0.4 \text { to } 0.3 \\
-0.5 \text { to }+0.5 \\
-2.7 \text { to } 6.7 \\
-0.4 \text { to }+0.5 \\
-0.17 \text { to }+0.37 \\
-3.9 \text { to } 1.4\end{array}$ \\
\hline
\end{tabular}

${ }^{*}$ Controls and alcoholics matched. VC-vital capacity; RV-residual volume; TLC-total lung capacity; TLCo-transfer factor for carbon monoxide. Conversion: traditional units to SI-Transfer factor: $1 \mathrm{ml} / \mathrm{min} / \mathrm{mm} \mathrm{Hg}=0.334 \mathrm{mmol} \mathrm{min}^{-1} \mathrm{kPa}^{-1}$.

is evident from the frequency of macrocytosis, abnormal results in liver function tests, and histologically proved liver damage (table 1). A liver biopsy was performed in 20 patients and findings were abnormal in all of them. A biopsy was not done in seven patients: one patient refused and four had severe coagulation defects, and in two plasma liver function tests gave normal results. One of these two patients had alcoholic macrocytosis, so that only one patient had no demonstrable laboratory abnormality due to alcohol abuse.

An excellent match was obtained between alcoholic and control patients with respect to age, smoking history, years of not smoking in the ex-smokers, and haemoglobin concentration (table 2). A match for race and sex was achieved in all cases. The mean daily alcohol consumption of the patients was approximately eight times that of the controls.

When questioned about respiratory symptoms, 14 alcoholics admitted to one or more symptoms; six had a cough; four complained of wheeze; three were dys- pnoeic on mild exertion, and eight had cough, wheeze, dyspnoea on mild exertion, and excessive sputum production. Of the patients with symptoms, nine were smokers, four were current non-smokers, and one had never smoked. The group with symptoms consisted of four smokers, six current nonsmokers, and three who had never smoked. The current non-smoking alcoholics had a group mean (SD) of 19.5 (13) pack years' history of cigarette smoking before stopping, compared with 29.8 (14) for the alcoholic group as a whole.

Pulmonary function was abnormal in 13 of the 27 alcoholics and in 15 of the control group. Results are shown in figure 1 . Though more smoking alcoholics than smoking controls had an isolated defect of TLCO, this was not statistically significant. Two alcoholics and one control subject had an $\mathrm{FEV}_{1} / \mathrm{FVC}$ ratio of less than $70 \%$; but none of them showed a reversible element, as defined by a change of more than $20 \%$ in the ratio after inhalation of salbutamol. There was no significant difference between alcoholics and controls

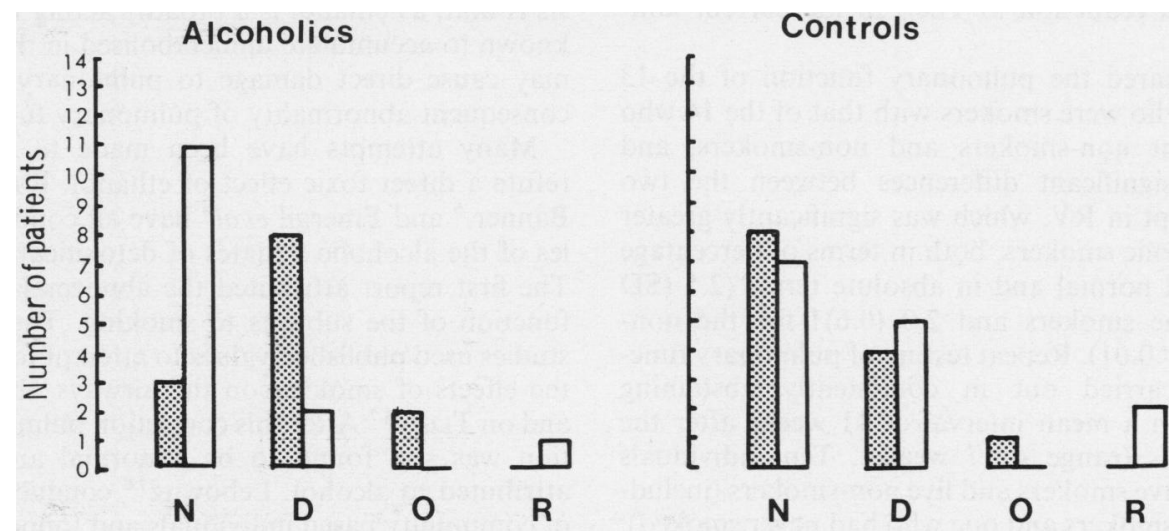

Fig 1 Pulmonary function of alcoholics and controls ( $\square$ non-smokers; 图 smokers). $N$-normal pulmonary function; $D$-isolated diffusion defect; $O$-obstructive airways disease; $R$-restrictive defect. 
B

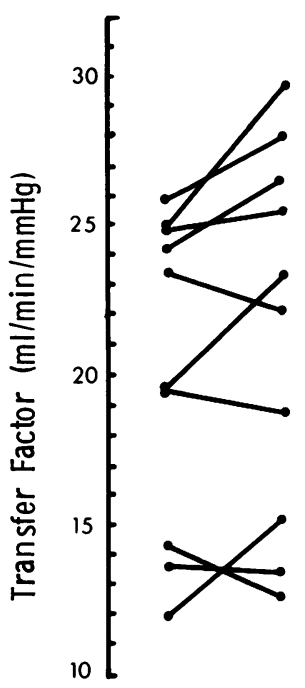

B

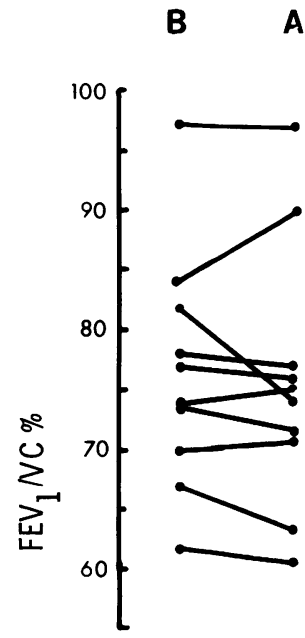

A
Fig 2 Transfer factor and ratio of $F E V_{1}$ to vital capacity $\left(F E V_{1} / V C\right)$ in 10 alcoholics before $(B)$ and after $(A)$ a period of abstinence from alcohol. in any other index of pulmonary function.

The alcoholics showed a significant reduction in mean $\mathrm{FEV}_{1}$, which was $91 \%$ of the predicted normal $(p<0.05)$. TLCo was also reduced, being $78 \%$ of the predicted normal $(p<0.001)$. This reduction was also present in the control group (mean FEV $3.0(0.9) 1$, with a predicted normal of $4.31 ; \mathrm{p}<0.03$ ). Mean TLC, RV, and FVC were within normal limits in both alcoholic and control groups. Resting arterial gas tensions were normal in all smoking alcoholics, and venous carboxyhaemoglobin concentrations ranged from $3 \%$ to $12 \%$. Analysis of the results for the current non-smoking and the non-smoking alcoholics showed that pulmonary function for the group was normal for TLCO, which was reduced to $85 \%$ of predicted normal $(p<0.001)$. This was largely attributable to a reduction in TLCO in the current nonsmokers.

We compared the pulmonary function of the 13 alcoholics who were smokers with that of the 14 who were current non-smokers and non-smokers, and found no significant differences between the two groups except in RV, which was significantly greater in the alcoholic smokers, both in terms of percentage of predicted normal and in absolute terms (2.5 (SD $0.7) 1$ for the smokers and $2.0(0.6) 1$ for the nonsmokers; $p<0.01$ ). Repeat testing of pulmonary function was carried out in consistently abstaining patients with a mean interval of 11 weeks after the original tests (range 4-17 weeks). Ten individuals attended-five smokers and five non-smokers (including four ex-smokers and one who had never smoked); the smokers had not altered their smoking habit and there was no mean change in any index of pulmonary function. The results for TLCO and $\mathrm{FEV}_{1} / \mathrm{FVC}$ are $\vec{\oplus}$ shown in figure 2 . The power of the tests to find a $10 \%$ change with $95 \%$ confidence was $>0.64$ and $>0.99$ respectively.

\section{Discussion}

There is no doubt that the prevalence of respiratory $\overrightarrow{\vec{B}}$ disease in alcoholics is high, but its aetiology has been $\exists$ the subject of debate. At least $80 \%$ of alcoholics? smoke, and therefore it is to be expected that their? pulmonary function will be abnormal. ${ }^{12} 13$ In addition, there is an association between hepatic cirrhosis 으 and hypoxia. ${ }^{14}$ An alternative explanation of the $\stackrel{\sim}{\times}$ observed respiratory disease of alcoholics has been $\bar{\sigma}$ advanced by Burch and DePasquale. ${ }^{4}$ Their hypothe- 3 . sis is that, as ethanol is a broadly acting toxin and is 0 known to accumulate unmetabolised in the lung, ${ }^{15}$ it may cause direct damage to pulmonary tissue and $\mathrm{O}$ consequent abnormality of pulmonary function.

Many attempts have been made to confirm or refute a direct toxic effect of ethanol. Rankin et al, ${ }^{2} \bar{N}$ Banner, ${ }^{5}$ and Emergil et $a l^{6}$ have all conducted stud- $\sigma$ ies of the alcoholic inmates of detoxification centres. $N$ The first report attributed the abnormal pulmonary function of the subjects to smoking. The latter two studies used published values to attempt to correct for the effects of smoking on the airways obstruction ${ }^{16} \frac{C}{D}$ and on TLCo. ${ }^{17}$ After this correction pulmonary func- $\stackrel{\oplus}{+}$ tion was still found to be abnormal and this was 7 attributed to alcohol. Lebowitz ${ }^{18}$ conducted a study of community based individuals and found an associ- $\stackrel{\mathbb{\triangle}}{\circ}$ ation between respiratory symptoms and drinking. In $\mathbb{\otimes}$ contrast, two large epidemiological studies of over 
1000 community based patients found no evidence of association between consumption of alcohol and airway obstruction. ${ }^{19} 20$

We carried out a case controlled study of alcoholics with carefully matched non-alcoholics, paying particular attention to their smoking habits. The inherent difficulty in inducing alcoholics to attend for sequential pulmonary function tests has meant that the number of patients studied is limited and consequently the power to detect a significant difference between the alcoholics and the controls is not as strong as we might wish. Nevertheless, we believe our conclusions to be valid. We have included as many non-smoking alcoholics as possible. Abnormal pulmonary function is more likely to reflect a direct toxic effect of ethanol in this group than in those who both smoke and drink. The control patients were drawn from the same population and resembled as closely as possible the alcoholics in all respects except their alcohol consumption. If ethanol were exerting a pulmonary toxic effect we would expect to find significantly worse pulmonary function in the alcoholics. As both the control and the alcoholic groups contained substantial numbers of smokers and exsmokers we did not expect pulmonary function to be normal in either group.

The pulmonary function of the combined group of alcoholic smokers and non-smokers is better than that in previously published studies. Emergil ${ }^{6}$ found abnormal pulmonary function in $70 \%$ of alcoholics (who included one non-smoker) and $64 \%$ of former alcoholics (nine current non-smokers). Banner found airways obstruction in almost half of his alcoholic patients; three of them were current non-smokers. Thirteen $(48 \%)$ of our alcoholics had abnormal lung function. Airways obstruction occurred in only two patients and an isolated diffusion defect was present in $10(37 \%)$. We believe the reason for the relatively low prevalence of abnormal pulmonary function in our group is the high percentage of non-smokers. From the previously published studies and our own there appears to be some relationship between the percentage of smokers and the degree of pulmonary abnormality found in any group of alcoholics. This is to be expected and such a relationship by no means excludes ethanol as a direct contributor to this abnormality. It does indicate, however, that smoking rather than ethanol is the dominant contributor.

One way of distinguishing between tobacco and alcohol related disease in alcoholics is to study only non-smoking alcoholics. Sarkar and Gupta ${ }^{21}$ have done this, though they do not state whether their patients were ex-smokers or never-smokers. Three of their 10 subjects did have minor abnormalities: one had a mild restrictive defect, one minimal expiratory flow limitation, and one air trapping. The pulmonary function of our non-smoking alcoholics is similar to that found by Sarkar and Gupta. We know from the frequency and severity of liver disease in this group that they were drinking sufficient ethanol to cause severe organ damage. The lack of demonstrable pulmonary disease in our non-smokers and in those of Sarkar and Gupta suggest that alcohol abuse alone is not a cause of serious abnormality of pulmonary function. Subdivision of the alcoholics into current smokers and non-smokers showed that pulmonary function was similar in the two groups except for RV, which was higher in the smoking alcoholics. This is not unexpected as RV is a sensitive descriminant between smoking and non-smoking individuals. ${ }^{22}$

We were impressed by the similarity of pulmonary function in the alcoholic and control groups (table 2). In the non-smokers, where we expected to detect any direct toxic effect of ethanol, pulmonary function was slightly better in the alcoholics than in the controls (fig 1). One of our never smoking alcoholics did show a restrictive pattern; this patient was female and Asian. Interestingly, two of the never smoking controls showed a similar defect: both were Asian and female. We have found it not unusual for Asians and particularly Asian women to show unexpected divergence from predicted normal values for lung function. This is perhaps because the normal range is not as well defined for this population as it is for the white European population.

In summary, we have found significantly worse pulmonary function in smoking than in non-smoking alcoholics but no difference between alcoholics and non-alcoholic controls matched for smoking history. We have found no evidence to support the view that ethanol causes lung damage directly or that it enhances the harmful effects of smoking, and conclude that the high prevalence of respiratory disease in alcoholics is largely due to their smoking habits.

We would like to thank Mrs Helen Moszoro and Mrs Ann Rhodes for their expertise in measuring the patients' pulmonary function, Ms Rosamund Greensted for typing the manuscript, and Dr D Altman for statistical advice.

\section{References}

1 Anonymous. Tuberculosis and the alcoholic [editorial]. Lancet 1978;ii:460-1.

2 Rankin J, Hale G, Wilkinson P, O'Day D, Santamaria J, Babarczy G. Relationship between smoking and pulmonary disease in alcoholism. Med J Aust 1969;i:730-3.

3 Ruff F, Hughes J, Stanley N, et al. Regional lung function in patients with hepatic cirrhosis. J Clin Invest 1971;50:2403-13.

4 Burch G, DePasquale N. Alcoholic lung disease-an hypothesis. Am Heart J 1967;73:148-9. 
5 Banner A. Pulmonary function in chronic alcoholism. Am Rev Respir Dis 1973;103:851-7.

6 Emirgil C, Sobol B, Heymann B, et al. Pulmonary function in alcoholics. Am J Med 1974;57:69-77.

7 Emirgil C, Sobol B. Pulmonary function in former alcoholics. Chest 1977;72:45-51.

8 Cotes J. Lung function: principles and application in medicine. 4th ed. Oxford: Blackwell Scientific Publications, 1979.

9 Medical Research Council. Questionnaire on respiratory symptoms (forms S and K 7/76). London: MRC, 1976.

10 Ogilvie C, Forster R, Blakemore W, Morton J. A standardised breath holding technique for the clinical measurement of the diffusing capacity of the lung for carbon monoxide. J Clin Invest 1957;36:1-17.

11 Miller G, Ashcroft M, Swan A, Beadnell W. Ethnic variation in forced expiratory volume and forced vital capacity of African and Indian adults in Guyana. Am Rev Respir Dis 1970;102:979-81.

12 Frans A, Stanescu D, Veriter C, Clerbaux T, Brasseur L. Smoking and pulmonary diffusing capacity. Scand $J$ Respir Dis 1975;56:165-83.

13 Beck G, Doyle C, Schacter E. Smoking and lung function. Am Rev Respir Dis 1981;123:149-55.

14 Daoud F, Reeves J, Schaefer J. Failure of hypoxic pulmonary vasoconstriction in patients with liver cirrhosis.
J Clin Invest 1972;51:1076-80.

15 Casier $H$. Accumulation of alcohol metabolites in the form of total lipids and fatty acids in the organism. Quarterly Journal of Studies in Alcoholism 1962;23:529-48.

16 Grimes C, Hanes B. Influence of cigarette smoking on the spirometric evaluation of employees of a large insurance company. Am Rev Respir Dis 1973;108:273-82.

17 Van Ganse W, Ferris B, Cotes J. Cigarette smoking and pulmonary diffusing capacity. Am Rev Respir Dis 1972;105:30-41.

18 Lebowitz M. Respiratory symptoms and disease related to alcohol consumption. Am Rev Respir Dis 1981; 123:16-9.

19 Cohen B, Celentano D, Chase G, et al. Alcohol consumption and airway obstruction. Am Rev Respir Dis 1980;121:205-15.

20 Sparrow D, Rosner B, Cohen M, Weiss ST. Alcohol consumption and pulmonary function. A cross sectional and longitudinal study. Am Rev Respir Dis 1983;127:735-8.

21 Sarkar T, Gupta V. Pulmonary function in non-smoking chronic alcoholics. Postgrad Med J 1980;67:96-106.

22 Becklake M, Permutt S. A ranking approach to evaluation of function tests as potential screening tests. In: Macklem $\mathrm{P}$, Permutt $\mathrm{S}$, eds. The lung in transition between health and disease. New York: Marcel Dekker, 1979. 